\title{
High Wall-Plug Efficiency 1060 nm High Power Semiconductor Laser
}

\author{
Jianjun Li, Yingying Fu, Yuancheng Wang, Donghai Si, Yan Li, Haikuo Wang, \\ Jun Deng, Jun Han \\ Key Laboratory of Opto-Electronics Technology (Beijing University of Technology), Ministry of Education, \\ Beijing, China \\ Email: s201502003@emails.bjut.edu.cn
}

Received 14 May 2016; accepted 22 August 2016; published 25 August 2016

\begin{abstract}
By analyzing the factors which affect the wall-plug efficiency of semiconductor Laser Diodes (LDs), a high efficiency $1060 \mathrm{~nm}$ LD was designed, including active region, waveguide layers, and cladding layers. The simulation result shows that the component of In in InGaAs in the active region cannot be too small, otherwise the thickness of InGaAs active layer will exceed the critical thickness, meanwhile the asymmetric large optical cavity can decrease the cavity loss effectively. The epitaxial structure was grown by MOCVD, experimental results of varying cavity length showed that the internal quantum efficiency reached $98.57 \%$, and the cavity loss was only $0.273 \mathrm{~cm}^{-1}$. Devices with $4 \mathrm{~mm}$-cavity-length and $100 \mu \mathrm{m}$-strip-width were fabricated, $47.4 \%$ wall-plug efficiency was reached under QCW pulse condition at room temperature, and the peak wavelength was $1059.4 \mathrm{~nm}$.
\end{abstract}

\section{Keywords}

Semiconductor Laser, Waveguides, Quantum Well, MOCVD

\section{Introduction}

$1060 \mathrm{~nm}$ semiconductor lasers are an important light source in military, medical, spectroscopy, material processing and other fields. Compared with Nd:YAG system, $1060 \mathrm{~nm}$ semiconductor lasers have the advantage of small size, high efficiency and light weight. Therefore, a wide range of studies have been carried out on 1060 nm high power semiconductor lasers in China and abroad. For high power semiconductor lasers, power conversion efficiency is a very important technical indicator. For example, if the output optical power is $6 \mathrm{~W}$, input power will be reduced from $15 \mathrm{~W}$ to $12 \mathrm{~W}$ when the power conversion efficiency is increased from $40 \%$ to $50 \%$, which can reduce $3 \mathrm{~W}$ invalid heat. Invalid heat not only reduces the efficiency of the device, but also increases the requirement of the heat dissipation package, reducing the reliability and lifetime of the device.

Therefore, improving power conversion efficiency is a long-term research for high power semiconductor laser [1]-[4].

Factors affecting the power conversion efficiency of the semiconductor laser are multifaceted, including the 
internal quantum efficiency, cavity loss, series resistance, threshold current and effective heat dissipation packaging measures, etc. [5]. By analyzing the factors affecting the power efficiency of the semiconductor laser, this paper designed the epitaxial structure of the high efficiency $1060 \mathrm{~nm}$ semiconductor laser, and carried out the fabrication of devices, then obtained the high power efficiency of the device.

\section{The Structure Design of Device}

The power efficiency of semiconductor laser $\eta_{c}$ is expressed as the ratio of output optical power and input electric power,

$$
\eta_{c}=\frac{P_{o p t}}{I_{o p} \cdot U}
$$

$I_{o p}$ is the device working current and $U$ is the device working voltage. $P_{\text {opt }}$ and $U$ can be expressed as [6],

$$
\begin{gathered}
\mathrm{P}_{\mathrm{opt}}=\eta_{d} \cdot \frac{\hbar \omega}{q} \cdot\left(I_{o p}-I_{t h}\right) \\
\eta_{d}=\eta_{\mathrm{i}} \cdot \frac{\alpha_{m}}{\alpha_{m}+\alpha_{i}} \\
\mathrm{U}=U_{d}+I_{o p} \cdot R_{s}
\end{gathered}
$$

$\eta_{\mathrm{d}}$ is slope efficiency, $\eta_{i}$ is internal quantum efficiency, $\hbar \omega$ is the photon energy, $I_{\mathrm{th}}$ is threshold current density, $\alpha_{m}$ and $\alpha_{i}$ are mirror loss and cavity loss, respectively. $U_{d}$ is intrinsic pressure drop, $R_{s}$ is the series resistance. Bring (2)-(4) into (1), it can get:

$$
\eta_{c}=\eta_{\mathrm{i}} \cdot \frac{\alpha_{m}}{\alpha_{m}+\alpha_{i}} \cdot \frac{\hbar \omega}{q\left(U_{d}+I_{o p} \cdot R_{s}\right)} \cdot \frac{I_{o p}-I_{t h}}{I_{o p}}
$$

As it can be seen in Formula (5), in order to obtain high power conversion efficiency $\eta_{\mathrm{c}}$, device is required to have high internal quantum efficiency $\eta_{\mathrm{i}}$, low cavity loss $\alpha_{\mathrm{i}}$, series resistor $\mathrm{R}_{\mathrm{s}}$ and threshold current $\mathrm{I}_{\mathrm{th}}$.

Based on the principle above, we designed a high efficiency $1060 \mathrm{~nm}$ high power semiconductor laser epitaxial structure shown in Figure 1, which the active region adopt InGaAs/GaAs double quantum well (QW) structure and well spacing is $100 \mathrm{~nm}$. In order to raise the COD standard, $2.2 \mu \mathrm{m}$ asymmetric large optical cavity

\begin{tabular}{|c|c|}
\hline $\mathrm{p}^{+}-\mathrm{GaAs}$ contact layer & $0.2 \mu \mathrm{m}$ \\
\hline \multicolumn{2}{|c|}{$\mathrm{P}-\mathrm{Al}_{\mathrm{x}} \mathrm{Ga}_{1-\mathrm{x}} \mathrm{As}$ transition layer0.1um } \\
\hline \multicolumn{2}{|c|}{$\mathrm{P}-\mathrm{Al}_{0.25} \mathrm{Ga}_{0.75} \mathrm{As}$ limiting layer $0.6 \mu \mathrm{m}$} \\
\hline i-GaAs waveguide layer & $0.9 \mu \mathrm{m}$ \\
\hline \multicolumn{2}{|l|}{ InGaAs DQW active layer } \\
\hline i-GaAs waveguide layer & $1.2 \mu \mathrm{m}$ \\
\hline $\mathrm{N}-\mathrm{Al}_{0.25} \mathrm{Ga}_{0.75} \mathrm{As}$ limiting layer & $0.6 \mu \mathrm{m}$ \\
\hline $\mathrm{N}-\mathrm{Al}_{\mathrm{x}} \mathrm{Ga}_{1-\mathrm{x}} \mathrm{As}$ transition layer & $0.1 \mu \mathrm{m}$ \\
\hline n-GaAs substrate & \\
\hline
\end{tabular}
structure has been used, the waveguide layer material is non-intentionally doped GaAs, and GaAs waveguide layer thickness of the $\mathrm{N}$-type and P-type side were $1.2 \mu \mathrm{m}$ and $0.9 \mu \mathrm{m}$, light confinement layer material is $\mathrm{Al}_{0.25} \mathrm{Ga}_{0.75} \mathrm{As}$. In order to reduce the series resistance of the device, insert a $0.1 \mu \mathrm{m}$ thick $\mathrm{Al}_{\mathrm{x}} \mathrm{Ga}_{1-\mathrm{x}} \mathrm{As}$ buffer layer between $\mathrm{GaAs}$ and $\mathrm{Al}_{0.25} \mathrm{Ga}_{0.75} \mathrm{As}$ confinement layer, and $\mathrm{Al}$ component $\mathrm{x}$ in a linear gradient change from

Figure 1. The structure of $1060 \mathrm{~nm}$ semiconductor laser. 
0 to 0.25 to reduce the voltage drop induced by the mutations heterojunction barrier. In addition, in the process of tube core fabrication, by using $100 \mu \mathrm{m}$ wide strip and $4 \mathrm{~mm}$ long cavity length structure to increase Ohmic contact area, in order to decrease series resistance. The following focuses on discussing how to raising $\eta_{i}$ and lowering $\alpha_{i}$. There is not specific discussion about how to lowering $I_{t h}$ because there are two point:

i) For high power semiconductor lasers, working current $I_{o p}$ is usually much larger than the threshold current $\mathrm{I}_{\text {th }}$, so in formula (5) $I_{\text {th }}$ has relatively small effect.

ii) raising $\eta_{i}$ and lowering $\alpha_{i}$ is consistent.

Factors that affect internal quantum efficiency $\eta_{i}$ include carrier leakage, radiative recombination and composite interface states. For the structure shown in Figure 1, waveguide layer also plays the role of active region in QW barrier layer. Well region is compressive strain material of $1060 \mathrm{~nm}$ transition wavelength, which barrier layer material is GaAs. For the InGaAs/GaAs heterojunction, through the ratio of conduction and valence bands $\Delta \mathrm{Ec} / \Delta \mathrm{Ev}=0.6 / 0.4$ [7] can estimate that the barrier height of electrons and holes are $152 \mathrm{meV}$ and $101 \mathrm{meV}$ at room temperature, The barrier layer can play a very good role in limiting the carriers in the well when $5.8 \mathrm{kT}$ and $3.8 \mathrm{kT}$.

Therefore, leakage of carriers is negligible. But strained may lead to misfit dislocations of InGaAs, and thus result in non-radiative recombination and interface state complex, this must be considered when QW designing. Compared with $980 \mathrm{~nm}$ semiconductor laser, $1060 \mathrm{~nm}$ semiconductor laser's active region require $\operatorname{In}_{\mathrm{x}} \mathrm{Ga} \mathrm{a}_{1-\mathrm{x}} \mathrm{As}$ with higher In component $x$. Therefore, for large strain materials $\operatorname{In}_{\mathrm{x}} \mathrm{Ga}_{1-\mathrm{x}} \mathrm{As}$ which was grown on GaAs substrate, its thickness must be limited to less than a critical thickness that can avoid relaxation dislocation. Figure 2 shows the simulation result of the relation between the critical thickness of $\operatorname{In}_{x} \mathrm{Ga}_{1-\mathrm{x}} A s \mathrm{~h}_{\mathrm{c}}$ and In constituent $\mathrm{x}$. Simulations used the formula given by Matthews and Blakeslee [8]. With the increase of $x, \operatorname{In}_{x} G_{1-x} A s \operatorname{strain}$ grown on GaAs substrate increase and the critical thickness of $\operatorname{In}_{x} \mathrm{Ga}_{1-x}$ As lawyer decreases. For biaxial compressive strain InGaAs material, the degeneracy of light and heavy hole band at the top of the valence band have eliminated, and the heavy-hole band is located above the light-hole band, therefore, the inter band transitions of InGaAs QW mainly occur between the first sub_level of conduction band $\mathrm{E}_{\mathrm{c} 1}$ and the first sub-level of valence band heavy hole $E_{v 1}$. Figure 2 also shows the relation between QW well width $\mathrm{w}$ and the composition of In $\mathrm{x}$ when the transition wavelength between $E_{c 1}$ and $E_{v 1}$ fixed to $1060 \mathrm{~nm}$. The specific simulation methods can be seen in document [9].

With the increase of $x, \operatorname{In}_{x} \mathrm{Ga}_{1-\mathrm{x}}$ As band gap decline, in order to get the same transition wavelength, it must enhance the quantum size effect, which is decrease well width w. As is shown in Figure 2, though $h_{c}$ and w in-

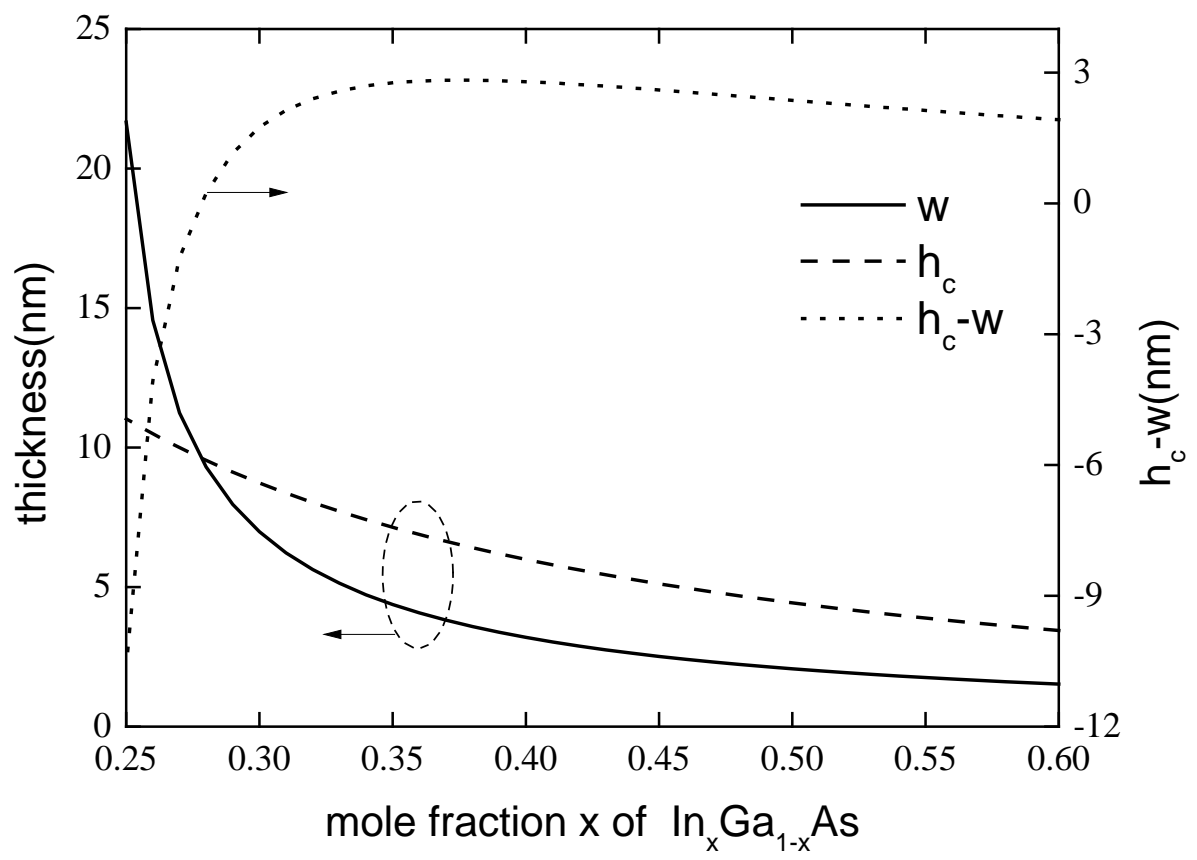

Figure 2. Relationship of well width and critical thickness with In mole fraction for $\operatorname{In}_{x} \mathrm{Ga}_{1-x} \mathrm{As}$ QW. 
crease with the drop of $\mathrm{x}, \mathrm{w}$ increased faster, especially when $\mathrm{x}<0.28, \mathrm{w}>\mathrm{h}_{\mathrm{c}}$, that mean the well width is larger than the critical thickness of the layer. Therefore, in order to get 1060nm transition wavelength, In component in $\mathrm{In}_{\mathrm{x}} \mathrm{Ga}_{1-\mathrm{x}} \mathrm{As}$ must more than 28\%. For epitaxial growth of strained materials, the more the strain layer thickness smaller than the critical thickness, the smaller the possibility of relaxation will be. For 1060 nm band transition wavelength, Figure 2 show relation between $\mathrm{h}_{\mathrm{c}}$ and $\mathrm{x}, \mathrm{w}$ and $\mathrm{x} . \mathrm{h}_{\mathrm{c}}$ and $\mathrm{w}$ get maximum value when $\mathrm{x}=0.38$. Although $h_{c}-w$ have maximum value when $x=0.38$, but meanwhile the well width is only $3.6 \mathrm{~nm}$, which is not easy to control in the actual extension process. Therefore in this paper the well width $\mathrm{w}$ is set to $6 \mathrm{~nm}$, and the corresponding values of $\mathrm{x}$ is 0.315 , the well width $\mathrm{w}$ is $75 \%$ of the corresponding values of $\mathrm{h}_{\mathrm{c}}$. This can effectively avoid strain relaxation in the active region of the quantum well, then reduce the non-radiative recombination and the interface state recombination, and then the internal quantum efficiency can be improved.

In order to reduce the cavity loss, on the one hand, it is necessary to improve the extension quality of the material when the material was grown. On the other hand, it is necessary to design the structure of the waveguide. Figure 3 shows the transverse fundamental mode near_field distribution along the direction of extension of the device which was obtained by using transfer matrix method to simulate [10]. Figure 3 also shows refractive index distribution near the active region. The selection of refractive index parameters in simulation can be seen in document [11].

Figure 3 shows that because it has adapt $2.2 \mu \mathrm{m}$ large optical cavity structure, 99.4\% of the light field are limited in the waveguide layer, thereby it greatly reduced the scattering and absorption losses introduced by doped confinement layer .

In addition, in the structure of device shown in Figure 1, we adapt the asymmetric waveguide structure, which the specific design can be seen in document [12]. As it can be seen in Figure 3, because of asymmetric waveguide, light field peak shift to $\mathrm{N}$-type waveguide side, in this way can reduce the light field distribution of P_type waveguide layer. Compare with electrons, holes have greater impact on scattering loss of light field, so it can effectively reduce the optical loss introduced by carriers by using asymmetric waveguide structure.

\section{Devices Fabrication}

As the device shown in Figure 1, we firstly use EMCORE D125 type MOCVD equipment for the epitaxial growth of the material. Group III source material are TMGa, TMAll and TMIn, Group V source material are high purity $\mathrm{AsH}_{3}$, N-type doping source is $\mathrm{SiH}_{4}$ diluted by $\mathrm{H}_{2}$, P-type doping source is $\mathrm{CCl}_{4}$, carrier gas is high purity $\mathrm{H}_{2}$ purified by palladium tube. Epitaxial temperature between $575^{\circ} \mathrm{C}-675^{\circ} \mathrm{C}$, growth rate is $5-7 \AA / \mathrm{s}$. In order to ensure uniformity of the epitaxial, substrate rotate at high speed of $1000 \mathrm{rev} / \mathrm{min}$.

Figure 4 is photoluminescence (PL) test results at room temperature after epitaxial. Peak wavelength is 1044 $\mathrm{nm}$ and Full Wave at Half Maximum (FWHM) is $23.4 \mathrm{~nm}$, corresponding to $27 \mathrm{meV}$, which is equivalent to the

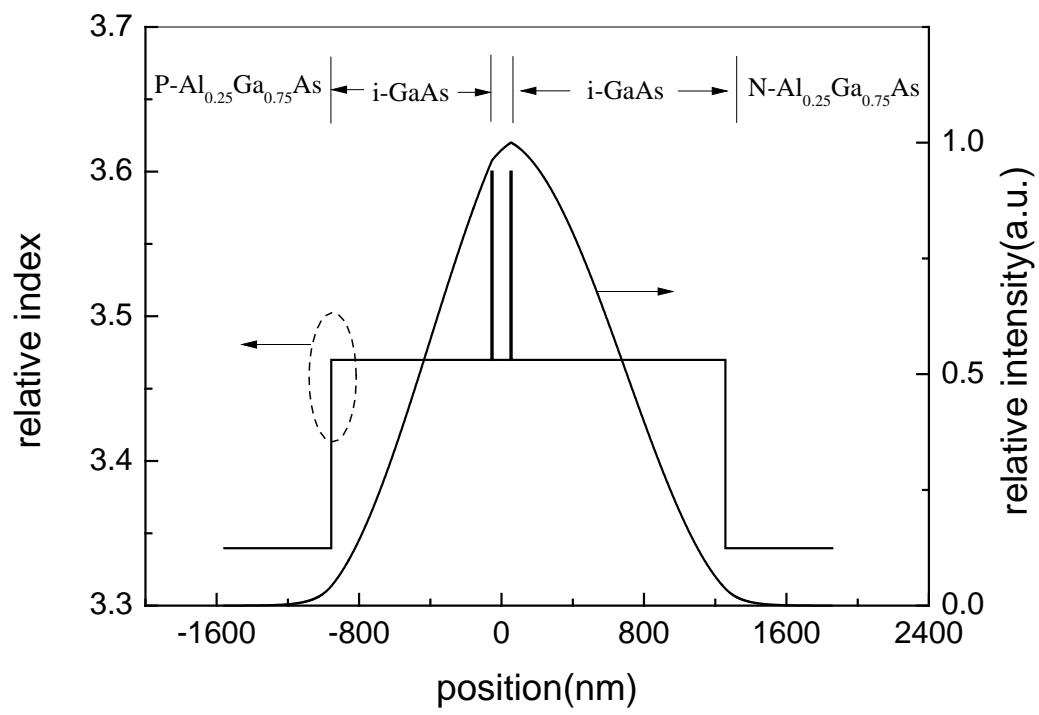

Figure 3. Distribution of the refractive index and fundamental mode near field. 


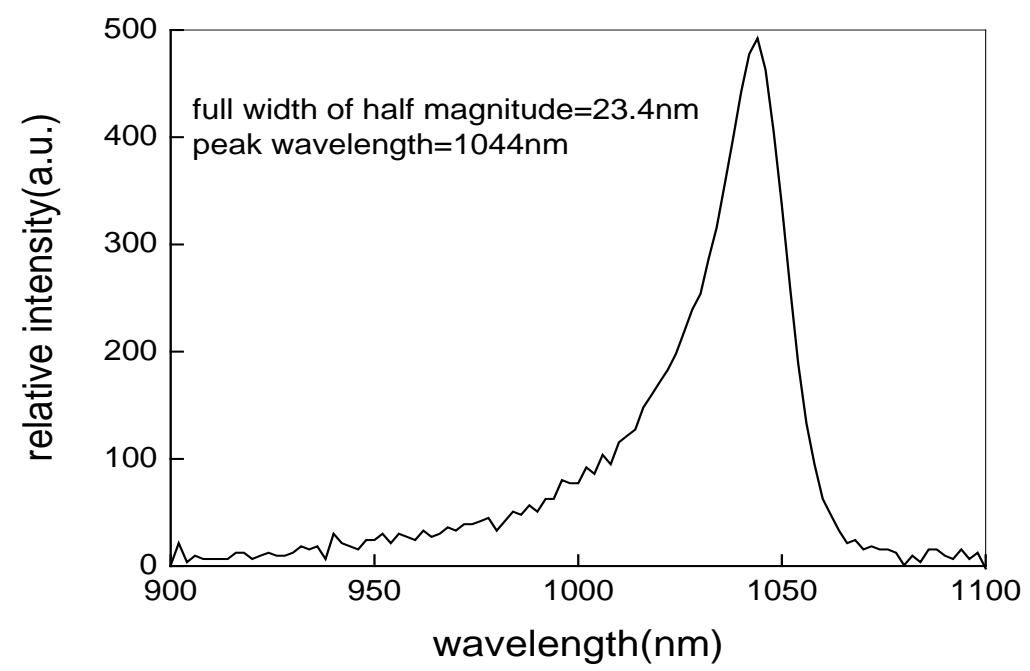

Figure 4. PL measurement result of $\operatorname{In}_{x} \mathrm{Ga}_{1-x} \mathrm{As} \mathrm{QW}$.

order of magnitude of electronic thermal energy kT at room temperature. This result shows that the quantum well material epitaxy has good quality.

Fabricate wide strip ridge devices after cleaning the epitaxial wafers. At first, form ridge stage with $540 \mathrm{~nm}$ height and $100 \mathrm{~m}$ width through corrosion. Then sputter $200 \mathrm{~nm} \mathrm{SiO}$ and by using lithography to form $95 \mu \mathrm{m}$ P-type electrode contact hole, after that, sputterg Ti/Au as the P-type electrode. Afterwards thin the substrate to $120 \mu \mathrm{m}$ and sputter AuGe Ni/Au as the N side electrode. After alloy annealing, cleavage it into different cavity length dies and sinter In solder at C-mount heat sink to test.

Figure 5 shows the test results of differential quantum efficiency $\eta_{d}$ of different device cavity length, because there is a linear relationship between $1 / \eta_{\mathrm{d}}$ and the cavity length $L$ [12], the figure also shows linear fitting result between $\eta_{d}$ and the cavity length L [13]. According to the fitting result, it can get internal quantum efficiency of the device $\eta_{\mathrm{i}}$ is $98.57 \%$, lumen loss $\alpha_{\mathrm{i}}$ just get $0.273 \mathrm{~cm}^{-1}$, fully demonstrated the device structure design is reasonable.

\section{Device Result}

Cleave the chip into $4 \mathrm{~mm}$ stripe for cavity surface coating, the reflectivity cavity surface and the high reflectivity cavity surface were $95 \%$ and $6 \%$ respectively. Then sintered single die and packaged in $\mathrm{TO}_{3}$ socket to test. Because it has not adapt any specially cooling measures, such as water cooling or air cooling, test has been carried out at quasi-continuous pulse condition, which the pulse frequency is $50 \mathrm{~Hz}$ and the pulse width is $100 \mu \mathrm{s}$.

Figure 6 is result of the devices light output power $\mathrm{P}$ and voltage $\mathrm{V}$ which were measured at different current. In 8 A current, the optical power output is $6.884 \mathrm{~W}$, the terminal voltage is $2.42 \mathrm{~V}$, the series resistance is 0.15 $\Omega$, slope efficiency is $0.942 \mathrm{~W} / \mathrm{A}$. The figure also shows the result of device power efficiency $\eta_{\mathrm{c}}$ in different current. With high internal quantum efficiency and low cavity loss, at $2.64 \mathrm{~A} \eta_{\mathrm{c}}$ reached a maximum of $47.4 \%$. By further optimizing the process to reduce the series resistance, the device is expected to further enhance performance.

In Figure 7, spectrum and device vertical far-field characteristics test result in 3 A working current were given in (a) and (b). Peak wavelength of the device is $1059.4 \mathrm{~nm}$, the spectral half width (FWHM) is $3 \mathrm{~nm}$. As a result of the large optical cavity structure, in vertical direction $95 \%$ of peak vertical divergence angle is $49.8^{\circ}, 50 \%$ peak divergence angle is only $24.6^{\circ}$, this is about to $30^{\circ}$ for conventional semiconductor laser.

\section{Conclusion}

For the fibrication of highly efficient $1060 \mathrm{~nm}$ semiconductor laser, it needs to rationally design the quantum well active layer of the device, the waveguide layer and the confinement layer. The point of active layer design is to rise internal quantum efficiency, because the strain of InGaAs active layer is larger, its thickness must be 


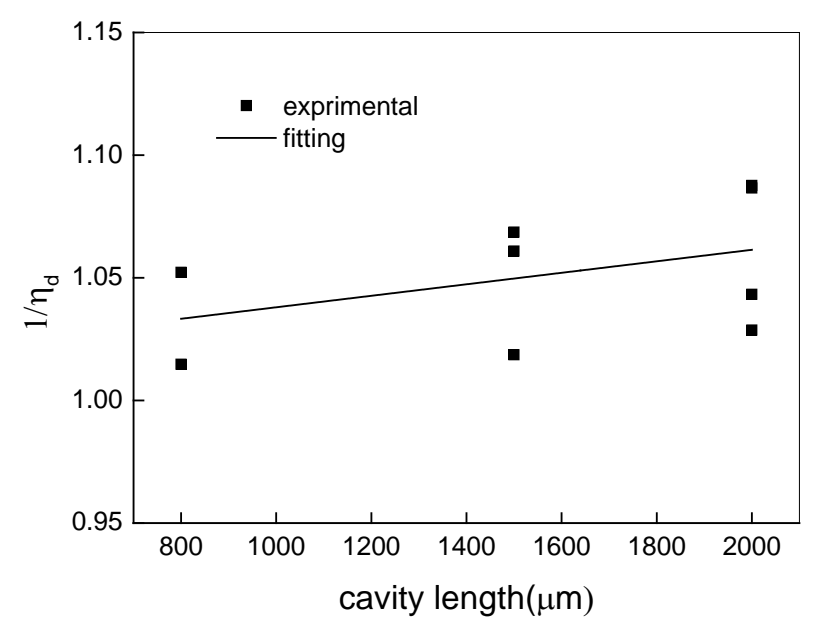

Figure 5. Experimental and fitting results of varying cavity length.

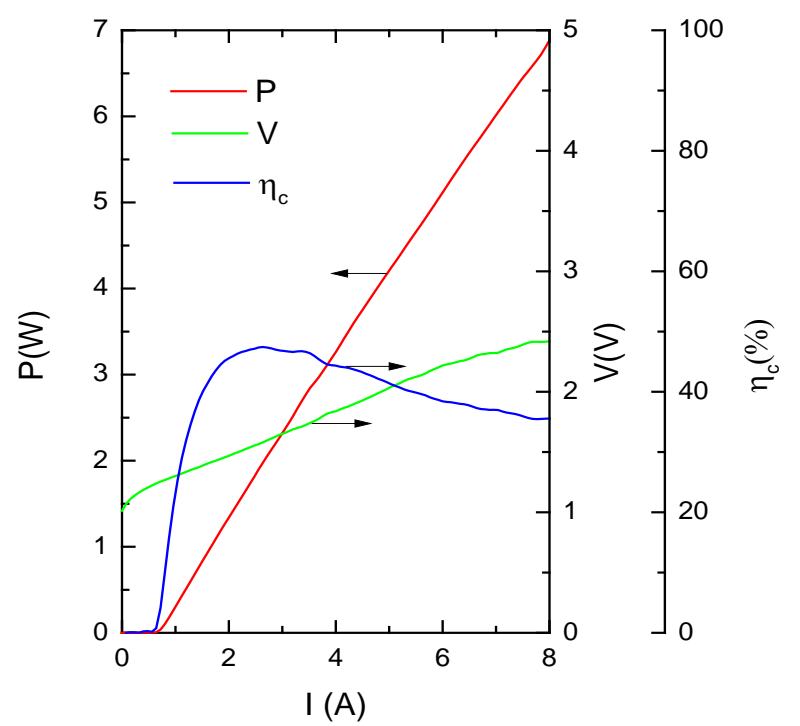

Figure 6. Measurement results of $P_{-} I$ and V_I characteristics.

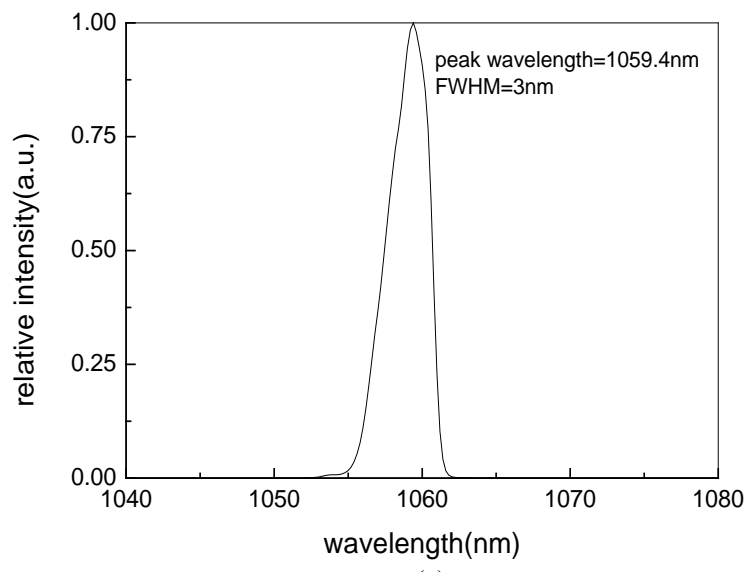

(a)

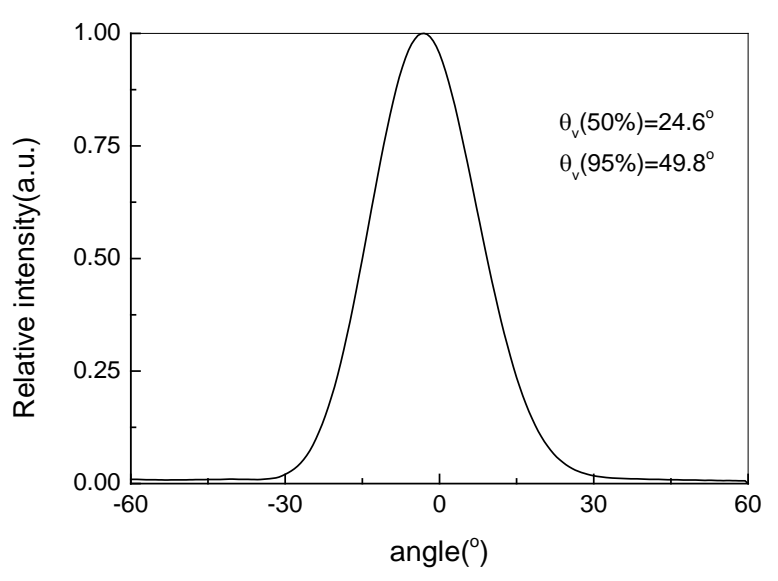

(b)

Figure 7. Spectrum and far field characteristics of the device. 
controlled in the critical thickness before dislocation relaxation occurs. The design of waveguide layer should consider reducing the cavity loss, and the symmetric waveguide of large optical cavity is an effective way of reducing the cavity losses. For confinement layer, in addition to doping, it will also pay attention to the transition between the GaAs contact layers to reduce the series resistance. Base on optimized device structure, material epitaxy, chip fabrication and package testing in this paper, we get $1060 \mathrm{~nm}$ semiconductor laser of $47.4 \%$ high power efficiency. At the same time, due to the large optical cavity structure, the vertical divergence angle of $50 \%$ peak is only $24.6^{\circ}$.

\section{Acknowledgements}

We thank the Beijing Municipal Education Commission for their financial support, which was provided as part of capacity improvement programs (PXM2016_014204_500026 and PXM2016_014204_500018).

\section{References}

[1] Li, T., Hao, E.-J., Li, Z.-J., et al. (2012) Optimization of Waveguide Structure for High Power 1060 nm Diode Laser. J. Infrared Millim. Waves, 31, 226-230. http://dx.doi.org/10.3724/SP.J.1010.2012.00226

[2] Pietrzak, A., Crump, P., Wenzel, H., et al. (2009) 55W Peak Power from $1100 \mathrm{~nm}$ Wavelength $60 \mu \mathrm{m}$ Broad-Area Laser Diodes Enabled by Reduced Carrier Accumulation in The Waveguide. Semiconductor Science and Technology, 24, 035020. http://dx.doi.org/10.1088/0268-1242/24/3/035020

[3] Pietrzak, A., Wenzel, H., Crump, P., et al. (2012) 1060-nm Ridge Waveguide Lasers Based on Extremely Wide Waveguides for 1.3-W Continuous-Wave Emission into a Single Mode with FWHM Divergence Angle of $9^{\circ} \times 6^{\circ}$. IEEE Journal of Quantum Electronics, 48, 568-575. http://dx.doi.org/10.1109/JQE.2012.2184526

[4] Wang, X.Z., Crump, P., Wenzel, H., et al. (2010) Root-Cause Analysis of Peak Power Saturation in Pulse-Pumped $1100 \mathrm{~nm}$ Broad Area Single Emitter Diode Lasers. IEEE Journal of Quantum Electronics, 46, 658-665. http://dx.doi.org/10.1109/JQE.2010.2047381

[5] Crump, P., Erbert, G., Wenzel, H., et al. (2013) Efficient High-Power Laser Diodes. IEEE Journal of Selected Topics in Quantum Electronics, 19, 1501211. http://dx.doi.org/10.1109/JSTQE.2013.2239961

[6] Bachmann, F., Loosen, P. and Poprawe, R. (2007) High Power Diode Lasers. Springer Science + Business Media, LLC., New York, 17-20. http://dx.doi.org/10.1007/978-0-387-34729-5

[7] Jogai, B. (1991) Valence-Band Offset in Strained GaAs-InxGa ${ }_{1-x}$ As Superlattices. Applied Physics Letters, 59, 13291331. http://dx.doi.org/10.1063/1.105490

[8] Matthews, J.W. and Blakeslee, A.E. (1974) Defects in Epitaxial Multilayers: I. Misfit Dislocations. Journal of Crystal Growth, 27, 118-125. http://dx.doi.org/10.1016/0022-0248(74)90424-2

[9] Shun Lien Chuang (1991) Efficient Band-Structure Calculations of Strained Quantum Wells. Physical Review B, 43, 9649-9661. http://dx.doi.org/10.1103/PhysRevB.43.9649

[10] Li, J.J., Chen, C.H. and Shen G.D. (2000) The RPS Method Applied to the Numerical Solution of Multimode Slab Waveguides with Complex Indexes. IEEE Journal of Lightwave Technology, 18, 1433-1436. http://dx.doi.org/10.1109/50.887195

[11] Kokubo, Y. and Ohta, I. (1997) Refractive Index as a Function of Photon Energy for AlGaAs between $1.2 \mathrm{and} 1.8 \mathrm{eV}$. J. Appl. Phys, 81, 2042-2043. http://dx.doi.org/10.1063/1.364443

[12] Li, J.J., Cui, B.F., Deng, J., et al. (2013) Asymmetric Super Large Optical Cavity 980 nm High Power Semiconductor Laser. Chinese Journal of Lasers, 40, 1102011. http://dx.doi.org/10.3788/CJL201340.1102011

[13] Casey, H.C. and Panish, M.B. (1978) Heterostructure Lasers, Part A. Academic Press, New York, 174-182. 


\section{Submit or recommend next manuscript to SCIRP and we will provide best service for you:}

Accepting pre-submission inquiries through Email, Facebook, LinkedIn, Twitter, etc.

A wide selection of journals (inclusive of 9 subjects, more than 200 journals)

Providing 24-hour high-quality service

User-friendly online submission system

Fair and swift peer-review system

Efficient typesetting and proofreading procedure

Display of the result of downloads and visits, as well as the number of cited articles

Maximum dissemination of your research work

Submit your manuscript at: http://papersubmission.scirp.org/ 